\title{
LAS MONARQUÍAS. EUROPA OCCIDENTAL EN LA TRANSICIÓN DEL S. XIII AL S. XIV
}

\author{
Odilo ENGELS
}

Si se quieren tratar las monarquías del s. XIII como factores políticos deben considerarse los siguientes fenómenos: en primer lugar, observamos la separación del Estado de la persona del monarca que comenzó a formarse durante el $\mathrm{s}$. XII para perfilarse en el s. XIII. Si durante el s. XII la persona del rey había representado al reino, a lo largo del s. XIII este último apareció como una entidad abstracta y supra-personal. Si en un principio "la corona» representaba el símbolo material de la soberanía, luego pasó a tener un significado de símbolo abstracto. En Inglaterra y Francia la nobleza creía tener que proteger a "la corona», la arbitrariedad del rey, para favorecer a los futuros sucesores al trono. En aquel momento «la corona» representaba los medios de poder, puestos a disposición de la monarquía, con los cuales ésta se mantiene vigente. Desde entonces el monarca utilizaba «la corona» como un símbolo abstracto para definir con ella el conjunto de sus derechos. Evidentemente se mantuvo la preocupación -algo más antigua y no desinteresada, que la nobleza sentía por los medios de poder-casi equivalentes a los derechos de la corona, frente a su cambio de significado. En este sentido dicho desarrollo desembocó en Hungría hacia 1400 en la acentuada oposición de monarquía y corona, representando la corona a la totalidad de la nobleza y no al rey.

Pasamos al segundo fenómeno: el creciente conflicto monarquía-nobleza, y monarquía-ciudades. Todos sabemos que el noble hacía tiempo que estaba obligado frente al soberano al consilium et auxilium, y esto no sólo era obligación a seguir, en guerra o en asistencia al tribunal regio, sino que a su vez el monarca dependía de la aprobación de la nobleza, como por ejemplo, antes de emprender una empresa bélica o la cesión de un territorio de cierta consideración. Este equilibrio más o menos intacto, se tambaleó en el s. XIII. El soberano fortaleció el principio monárquico y adoptó los primeros rasgos absolutistas; se consideraba poseedor de todos los poderes del Estado, 
rindiendo cuentas únicamente ante Dios. La nobleza no se rebeló directamente contra estas ideologías monárquicas, pero utilizaba las debilidades y los fallos políticos del rey para la consecución de sus anhelos de participación.

El ejemplo más cercano, la corona de Aragón, es mejor conocido por ustedes. Es un particular ejemplo de la capacidad de permanencia de la nobleza. Pedro III estuvo casado con Constanza, hija de Manfredo de Sicilia. De ahí su interés por Sicilia como heredero de los Hohenstaufen. A los tres años de ascender al trono, esto le llevó a imponer a su hermano Jaime II de Mallorca las obligaciones feudales sin considerar el último testamento de su padre Jaime el Conquistador. Las Vísperas Sicilianas de 1282 fueron preparadas por él en conspiración con los magnates sicilianos; y pese a que el complot se convirtió apresuradamente en una rebelión abierta, Pedro consiguió que la isla quedara en su poder. Era de esperar que el Papa Martín IV reaccionara con la excomunión de Pedro y con el entredicho de la isla. Sin embargo, el siguiente paso de la "Curia Romana» conllevó serias dificultades, pues consistió en liberar a los ciudadanos de la corona de Aragón de su juramento de fidelidad al rey y ofrecer la corona a un hijo del rey de Francia. Jaime de Mallorca se puso inmediatamente de parte del rey francés, con lo cual las rutas marítimas de Barcelona a Sicilia quedaban amenazadas. Los altos cargos de Aragón se mantuvieron reservados frente a la política mediterránea por lo que Pedro tuvo que unir la empresa siciliana con un viaje-cruzada a Túnez. Ante esta situación, a Pedro no le quedó más elección que declarar mediante un privilegio general el reconocimiento de los derechos especiales de la nobleza aragonesa y de las ciudades, hecho que había sido demandado reiteradamente por los representantes del «Privilegio General» de octubre de 1283, decretado en Zaragoza, y prestar conformidad a una convocatoria periódica de las Cortes, cuyas fechas ya no eran decisión exclusiva del soberano. De forma análoga, aunque no tan general, tuvo que acceder igualmente a las demandas de los representantes de las ciudades catalanas. El hijo de Pedro, Alfonso III, se vio obligado a dar nuevos pasos porque Castilla se aproximaba a la corona francesa, vislumbrándose con ello una guerra entre Aragón y Castilla. No sólo aprobó en las Cortes de Zaragoza de 1287 los privilegios de la Unión concedidos por su padre, que se comprometió a enfrentarse a miembros de la unión aragonesa y de las Cortes, únicamente con la conformidad de Justicia de Aragón; sino que además tuvo que aceptar la posibilidad de que la Unión pudiese derrocarle como rey por motivos legales. En mi opinión ningún otro reino evolucionó tanto en la dirección de una monarquía constitucional. Hablar en términos de fuerza o debilidad del poder real significa quizás no disponer de la adecuada escala de medida; por contra, si se toman en consideración tales hechos bajo el aspecto de colaboración interna para la consecución del equilibrio en reparto de poder, entonces, la corona de Aragón evolucionó conforme a las tendencias de aquel tiempo.

Recordemos la Carta Magna inglesa de 1215. En primer lugar, este documento persiguió el reconocimiento de los derechos que el monarca debía asegurar a los barones, teniendo en cuenta la creciente necesidad de recursos. Esto anuncia el cambio en el comportamiento entre reino, nobleza, iglesia y ciudad. La Constitución de Paper de 1244 no iniciaba orden alguno, sólo era una propuesta que insinuaba sus 
contornos. El rey Enrique III debía ser supervisado en sus negociaciones referentes al reinado por una comisión formada por barones. En las Provisiones de Oxford de 1258, Enrique debía admitir un consejo de 15 miembros, que dirigía la decisión del rey respecto los asuntos del reino inglés. Pero la oposición de la nobleza se dividió cuando el anglofrancés Simón de Monfort se puso al mando de los radicales; a su fallecimiento (1265), en la guerra civil el poder real resurgió aún con más ímpetu de entre las turbulencias. Por un lado el Estatuto de Marlborough (1267) concedía al rey la posibilidad de ejercer la soberanía sin límites ni impedimentos; por el otro lado Enrique garantizaba el mantenimiento de las audiencias de consejos apoyadas en las Provisiones de Marlborough. Así pues, las negociaciones reales, cada vez más complicadas, aumentaban las necesidades de capital del monarca, favoreciendo la disposición a comprometerse. Desde 1272 Eduardo I, hijo de Enrique, no tuvo otra alternativa que perseguir sobre esta base una política de consolidación mediante convenios, aún sin dejar de acentuar sus prerrogativas reales. Sólo así pudo soportar los años difíciles a finales del S. XIII, cuando tuvo que llevar a cabo las costosas guerras de Gales, Escocia y en la Gascuña. No tuvo tanta importancia que la Carta Magna fuera recordada de nuevo en 1297 y 1300 mediante los poderes importantes de la población. Las medidas legales de las regulaciones eran leves. No obstante, se observaba claramente una tendencia a la unión de personas que finalmente formaban las communitas regni, para lo cual fueron admitidos cada vez más representantes del commons. La función del parlamento como origen de consejo y tribunal se extendía hacia una instancia de decisión e indirectamente de control respecto a las cuestiones financieras, y sobre todo para las peticiones de individuos o comunidades.

Francia evolucionó sin obstáculos, aún mostrando una base paralela. Bajo el mandato de Luis IX, el legislativo borgoñés hizo constar en el año 1256 como único monarca de su reino al soberano francés, que no reconocía la superioridad de nadie en los asuntos mundiales; solamente él servía al bienestar público, porque la patria communis era idéntica a su reino por lo que se anteponía a la patria regional. Este concepto sobrepasó la transición al S. XIV, aunque las escalas éticas no fueron tan altas como las que vivió Luis IX. En 1247 este monarca mandaba comisarios a todas las regiones del reino para controlar las actividades de los bailes y de los funcionarios reales con el fin de solventar malentendidos. La repetición anual de dichas visitas intensificaban la reforma del sistema, que quedó reflejado en las ordenanzas sobre obligaciones de los bailes y de la Sennenschale de 1254 y 1256 . No sólo en este caso el rey obraba sin consultar con los barones convencido de que sus deseos coincidían con el bienestar común. Al igual que las ordenanzas del emperador Federico Il éstas seguían tratando asuntos morales como juegos de azar o blasfemias y sobre todo particularidades legales como la sustitución del duelo por el procedimiento de inquisición. Estas medidas sólo eran válidas en el reino. Aún así se sobrepasó la frontera, pues se podía apelar al parlamento por falseamiento o negación de derechos en el territorio de un vasallo. En un principio, Luis no violó la juridicialización, pero las numerosas posibilidades de apelar directamente ante el rey reducía notablemente el peso de sus señorías. A esto se suma la formación de los legisladores, sobre todo, aquellos 
juristas formados según el derecho romano. Su creciente número permitió, desde Felipe IV, la organización de cámaras; por consiguiente se consumó paso a paso la separación del poder ejecutivo y la administración. Para que la dirección no pudiese dependizar al soberano, se modificó la "curia regis" mediante su extensión a nuevos grupos, como las ciudades. Cuando se convocaban, era decisión del rey; los participantes de las reuniones se unían en representación de su états; las proposiciones del rey eran asesoradas por separado, al igual que las exposiciones de las conclusiones. Estas últimas no tenían por qué ser aprobadas por el monarca. En comparación con Inglaterra, el monarca francés disfrutaba de un campo de actuación mucho más amplio.

La evolución en Castilla habría sido semejante si la relación con la nobleza no hubiese sido tan tensa. En la Guyenne se formaba una residencia armada, y en Flandes en 1302, un ejército nacional formado por fuerzas ciudadanas se rebelaba destruyendo un ejército real de caballeros. A continuación se han de tener en cuenta las alianzas entre la nobleza por la defensa del centralismo real; pero el sistema de ordenanza sufrió una crisis amenazante en Francia motivada por la guerra de los Cien años a mediados del s. XIV. En Castilla, en cambio, todo pareció ocurrir medio siglo antes. Como personaje clave destaca Alfonso $X$ el Sabio quien se consideraba representante de Dios y sostenía ya pensamientos que Juan Gil de Zamora manifestaba poco después ante Sancho IV. El rey se encontraba entre Dios y el hombre, Dios le ofreció a él los imperios, por lo cual podía esperar de sus habitantes obediencia absoluta y disposición de sacrificio hasta la muerte. No fue el fecho del imperio lo que le trajo dificultades con la nobleza, sino la legislación. La antigua nobleza - como la denominaba Salvador de Moxó- se diferenciaba antes del s. XII por basar su autoridad en dominio y laboriosidad lejos de la corte; pero bajo el imperio de Alfonso VIII tuvo que reunir sus antiguos derechos en el «Fuero viejo". Alfonso $X$ se impuso a esto redactando en 1265 el prólogo y el primer tomo del "Libro del Fuero" de Fernando III con el sentido de aumento de las competencias del poder del rey, sin tomar por ello contacto con la nobleza. Ante este hecho, se encontró con una creciente protesta hasta que en 1272 tuvo que retirar su versión por reconocimiento expreso de los antiguos privilegios. El Orden del rey estaba acompañado de medidas económico-políticas que favorecían a las ciudades en perjuicio de la nobleza, porque amenazaban con romper las estructuras tradicionales monárquicas. Lo mismo sucedía con las medidas de centralización, la curia regis fue transformada en una administración jurídica de la corte y hacia los intereses de la autoridad, la administración financiera fue racionalizada y la administración territorial totalmente reorganizada. Pero no sólo esto llevó a las rebeliones de la nobleza, sino también una lealtad menguante entre las potentes familias nobles. El cambiante comportamiento de Castilla con la corona de Aragón estaba cargado de peligro hacia un pacto entre el monarca y una significativa familia noble o grupo de nobles para perjudicar al monarca. Esta inseguridad culminó en 1275, cuando el futuro sucesor del trono, Fernando de la Cerda, cayó en la batalla contra los moros, y Alfonso $X$ no tuvo en cuenta la descendencia de éste, tal como lo había previsto la corte de Palencia de 1253, sino a su segundo hijo Sancho IV. Como la familia de los Lara apoyaba a los hijos de Fernando, Sancho se afilió con los Haro, rivales de 
los Lara; ya que Haro como soberano de Vizcaya podía darle la oportunidad a Sancho de tomar influencia en el reino de Navarra, el rey de Francia se puso a disposición de los Lara. Con ello el reinado se rebajó literalmente a liderar a una de las partes en la guerra civil. Aún fue peor, porque Alfonso creía tener que ser flexible ante los consejos del rey francés después de que las Cortes de Segovia reconocieran a Sancho como futuro sucesor de la Corona, consideró sus medidas de centralización por transigencia y pensó en el reparto del reino entre Sancho y los hijos de Fernando de la Cerda. Lo único consecuente era que en 1282 en Valladolid Sancho destituyó del cargo a su padre por incapacidad. Por consiguiente, Alfonso desheredó a su hijo y nombró sucesor a su hijo mayor, Fernando, con lo cual demostró lo inútil que había sido su política en los últimos siete años.

Aunque Sancho IV acabó imponiéndose, la cuestión de la sucesión legítima del trono no fue resuelta, y ésto pronunciaba la oposición entre los Haro y los Lara. Desde el punto de vista del $\mathbf{s}$. XIII se podría lamentar que las diferencias, dentro de la familia real, por la inclusión de la nobleza, no permitían al reino llegar a la estabilidad. Desde el punto de vista del s. XIV se reconoce en las turbulencias del saliente s. XIII un comienzo, convertir la nobleza en corte, también llamada «nueva nobleza», que se estableció como servicio en la corte. Para ello se necesitaba en Castilla la nueva dinastía de los Trastámara, que no se vio atacada por la dichosa cuestión del sucesor del trono. Pero no sólo eso, importante fue también la decisión de la evidencia soberana. Se debe conceder el mérito a la monarca María de Molina por haber guardado la corona intacta a su hijo Fernando IV, pero no pudo remediar que, por miedo a perder sus privilegios y en vista de la unión de las ciudades en Hermandades para la mayor fuerza de imposición, que la nobleza sustituyera a los funcionarios reales por representantes propios. Sin tener en cuenta el peligro de caer en una dependencia total, debía surgir la cuestión de la postura del rey en sentido no absolutista. Juan Manuel, un sobrino de Alfonso $X$, no dudaba de la delegación de Dios a través de un monarca y de la obligación de la nobleza respecto de él, pero ésta tenía un derecho, rebelarse contra el rey cuando existiera una gran pérdida de su honor o naciera un daño por su obligación de lealtad. Aquí se presuponía la igualdad de los hombres ante Dios, que permite únicamente diferentes obligaciones dentro de una sociedad, para las cuales existía una misión especial y natural. De esta manera tan moderada, casi humilde de formular estos pensamientos, justificaron la idoneidad del cargo del rey, y efectivamente, Enrique de Trastámara utilizó más tarde este argumento en la toma de la corona.

Pero la teoría del reinado de Castilla no llegó tan lejos como el «Pactismo» de la corona de Aragón. En su obra más importante «Lo Crestià» el franciscano valenciano Francesc Eiximenis subordinó al rey a las leyes y encontró en las Cortes el órgano en cuya jurisdicción caía el poder de veredicto y castigo en caso de incumplimiento de las leyes por parte del soberano, ya que éstas convirtieron al rey en su monarca y así podían destituirlo. Según su punto de vista el núcleo de las Cortes estaba formado por la totalidad de las ciudades; en las regiones valenciano-catalanas dominaba casi una tendencia republicana. En Castilla en cambio se consideró la violenta supresión de 
Pedro el Cruel mediante un tiranicidio como salida excepcional. Ya la reducción de las asambleas populares a cabildos, con los funcionarios reales como regidores en segundo plano, reducción realizada por Alfonso XI con el fin de favorecer un control estabilizado desde la Corte, muestra claràmente cómo se interrumpió el camino hacia una monarquía constitucional.

Para demostrar que las tensiones internas no eran sólo consecuencia del constante crecimiento de necesidades financieras y de una administración cada vez más complicada, deberíamos considerar al papado de aquellos tiempos. Como el papado tenía los mismos ideales monárquicos que los soberanos de aquel entonces, no es de extrañar que apoyara a ciertos monarcas en sus diferencias con la nobleza. Aquí debe bastar con el ejemplo de Navarra. Con el fuerte aumento del "Fuero Antiguo", creado en 1238 como meta, tuvo Teobaldo II que jurar en 1253 antes de su proclamación que respetaría todos los derechos y libertades de los habitantes y anularía todas las injusticias implantadas por sus antecesores. Solamente después de su juramento los navarros estaban dispuestos a hacer su juramento de fidelidad. Si además se le acerca a la justificación histórica de los «Fueros Generales», de que los montanyeses hubieron reconquistado su país con sus propios medios a los sarracenos y luego elegido un rey, que primero tuvo que jurar sus derechos, entonces el monarca aparece, independientemente a la monarquía hereditaria, como un delegado del pueblo. Fue razón suficiente para el Papa Inocencio IV para tomar en 1255 a Teobaldo II bajo su protección y autorizar al obispo a desligar al rey del juramento de la coronación, con lo cual se reducía la capacidad del ejercicio de su cargo.

Precisamente Inocencio IV mostraba comprensión por la difícil situación del rey de Navarra; él mismo no nombró ningún cardenal durante su pontificado, porque éstos ya no se consideraban como súbditos del cargo papal. Con ello surgió paulatinamente un contrapeso al plenitudo potestati. Ya bajo Inocencio III los canonistas pedían un cambio en el comportamiento de la autoridad y en el nombramiento del Papa. ¿Acaso justificaba la ilimitada autoridad del Papa poder conceder permisos según le venían en gana, o debía respetar las normas del plenitudo potestati en cada nombramiento. Inocencio IV, excelente jurista, desarrolló a partir de un ejemplo de la historia de Aragón una primera solución: los religiosos hacían votos de pobreza y soltería según mandaban las reglas de su orden. El Papa podía dispensar de esto si la boda del monje fuera la única solución para continuar la dinastía. Las utilitas de la generalidad podían anteponerse al bonum individual del voto. Inocencio sólo podía llegar a esta conclusión porque diferenciaba muy bien entre derecho divino, derecho natural y derecho positivo. Los decretalistas entre los canonistas, defensores activos de la autoridad papal, encontraron en los decretistas, que se consideraban como las fuentes principales de las decisiones del concilio, un competidor con posiciones contrarias. Éstos perseguían la idea que el Vicarius Christi fuera una fuente de derechos ilimitada, en que quedan recogidos todos los derechos positivos; éstos se hacían cargo de difundir aspectos morales como otros criterios de conclusión. Desde siempre debía cuestionarse ante el otorgamiento de una dispensa si la decisión estaba permitida, si era adecuada y si servía al amor, para que correspondiera a las utilitas. El tercer punto, las caritas. Éstas 
eran cada vez más importantes porque asociados al scandalum resultaban negativas. Si un obispo antepusiera una peregrinación, cuya finalidad se había perdido prematuramente desde le punto de vista de las Utilitas formales, podría argumentarse una dispensa, pero no se podría remediar la impresión de un scandalum si se tratara de un novicio. En tal caso por el amor al prójimo se concibe una dispensa.

Un amplio consenso entre decretalistas y decretistas se encontró a lo largo del s. $X V$. En estos tiempos los cardenales volvieron a encontrar el camino a la reducida escala de su declaración. Una característica de la idealización del Papa es la amenaza de independencia de éste por seguir, medidas positivistas. Otra característica es volver a llevarla a su origen adaptándola a su correspondiente estructura. Con ello se reflejaba la crisis con sus motivaciones opuestas en las monarquías occidentales. Intentando reunir todo ello en un punto, la crisis queda reducida a la oposición entre la persistencia del derecho consagrado y la cuestión de si la autoridad o la institución es capaz de realizar una función práctica, y en qué medida.

Debemos tener en cuenta un tercer fenómeno: la casa real. No es igualable a una dinastía y tampoco es idéntica al reino. Como ejemplo, la corona de Aragón, donde antes se formaron los elementos de una casa real. Pero tanto ella, la corona de Aragón, como los reyes de Castilla, antes de los Trastámara, carecía de un identificativo dinástico que reuniese a todos los miembros, como por ejemplo, Kapetinger, Habsburger, Plantagenet, etc...

Comencemos aun así por la corona de Aragón. Ya en el s. XII, después del que Ramón Berenguer III adquiriese el condado de Provenza mediante su boda en 1112, la manera de pensar en las casas nobles de los condes de Barcelona jugó un papel importante. Así pues, de aquí en adelante, valía como una provisión para el segundo hijo, con derecho a reversión del cargo principal, en caso de que la familia se quedase sin herencia. La casa de Barcelona perdió prácticamente la Provenza cuando en 1245 Beatriz de Provenza, hija heredera, contrajo matrimonio con el hermano del rey Carlos de Anjou y éste le jurase fidelidad. En 1137 se constituyó la unión de Aragón y Cataluña. Mientras Ramón Berenguer vivía, la futura relación legal de la dos naciones quedaba indefinida. Ya porque el conde de Barcelona como princeps era solamente el delegado de su esposa Petronila, era inimaginable que las estructuras internas de los dos países se asemejaran. Pero tampoco se intentó realizar tal acercamiento bajo el reinado de Alfonso II, ya que al parecer la idiosincrasia de las dos naciones de la Corona era independiente de las características biológicas de las familias soberanas en sentido de una institución suprapersonal. El estado todavía en auge de la casa noble era incapaz de homologar los diferentes documentos legales, aun procediendo de territorios vecinos. Sólo así se puede entender la inhabitual transición de Ramón Berenguer IV a Alfonso II. Ramón Berenguer asignó a su hijo mayor, también llamado Ramón, en el testamento Aragón y Cataluña, y a su hijo segundo Pedro el condado de Rosellón y Cerdeña así como los derechos sobre Carcascana y Narbona. En cambio Petronila pensaba en el destino de la dignidad real de su casa paterna, porque en su testamento de 1164 llamó a su mayor Ildefonsus, y al que el padre llamaba Pedro, apareció con el nombre de Ramón Berenguer. Inequívocamente los dos hijos, de la casa de Barce- 
lona y de la casa de Aragón, debían seguir siendo los dirigentes; para el padre la tradición de Barcelona tenía prioridad, en cambio la madre pensaba con más previsión. Con los cambios de nombre en relación a los dos países, Aragón, con su dignidad consagrada no sólo recibía prioridad, sino también cambió el nombre de Pedro por Alfonso. Pedro debío recordar al Batallador cuando este legó su reino impropiamente a las Órdenes Militares, cosa que también podía haberse tenido en cuenta para la elección del nombre de Ramiro, padre de Petronila; aunque éste como religioso debió haberse dispuesto para la continuación de la dinastía ya que también resultaba idóneo para un recuerdo glorioso. Al menos en la casa real se observaba una fusión que creó un símbolo estable. Hasta entonces San Juan de la Peña era para los reyes de Aragón sinónimo de sepultura y Ripoll para los condes catalanes, sobre todo para la casa de Barcelona. En cambio Alfonso II creó en Poblet un monumento fúnebre para todos los monarcas de la Corona.

Elegir Poblet, en el obispado de Tarragona, no fue mera coincidencia. En 1170 Alfonso Il le escribió a Guillermo de Tarragona que la ciudad de Tarragona caput totius regni mei fore dinoscitur..., qui eam destruit, caput meum destruit. Esto parece ser la clave de la estructura interna de la corona de Aragón. Pocos años antes de la muerte de Ramón Berenguer IV se establecieron apostólicamente las fronteras de la provincia eclesiástica de Tarragona. Se orientaban, con pocas excepciones, según los límites de Tarraconensis de la antigüedad tardía. Su parte norte, que pertenecía a la provincia eclesiástica de Narbona, se agregaba a la casa de Barcelona; molestamente se desviaba a la frontera provincial para no dividir el condado de Cerdeña. Esto también explica la situación de Mallorca. Jaime I legó en su último testamento la isla como reino propio de su hijo, también llamado Jaime, y le concedió poderes de la corona al norte de las cimas de los Pirineos. Jaime II debía poseer las partes en tierra firme como feudo de los condes de Barcelona, y sin dependencia feudal las islas de Mallorca y Menorca. Aunque en el año 483 tuvieron obispo propio no fue así en las listas de firma del Collectio Hispana. La jurisdicción de aquellos lugares fue prometida mediante privilegios papales en 898 al obispo de Gerona y en 1068 al obispo de Barcelona. Después de la reconquista de Mallorca, Jaime l estableció una sede episcopal en Palma, mientras que los obispos de Tarragona, Barcelona y Gerona bloquearon mutuamente sus derechos sobre Mallorca mediante una inútil disputa y el Papa estaba dispuesto a ligar el nuevo obispado inmediatamente a la sede papal. Cuando la causa siciliana envió ayuda, el camino hacia un reinado independiente mallorquín quedaba abierto. Pero la idea del derecho sobre la casa era tan fuerte que Pedro III indicó con el poder de sus títulos un rex Maioricarum en 1276 un día antes de su coronación en Zaragoza; esto es, agregó Mallorca a la corona de Aragón, y en 1276 obligó a su hermano con el contrato de Montpellier a reconocer su dependencia feudal. En el s. XIV el feudo al parecer y en vista de su extensión a Cerdeña y Córcega, ofrecía poca seguridad; además el contrato de unión de 1309 concedía la soberanía sobre Aragón, Cataluña y Valencia a una única persona, por lo cual en 1349 a través de Pedro se sometía Mallorca eliminándose como reino. De aquí en adelante se representaba su población en las Cortes de Barcelona. 
De esta manera Sicilia perduraba como única línea colateral de la casa de Barcelona hasta que Martín, por entonces rey de Sicilia, tomaba en 1396 la corona de Aragón tras la repentina muerte de su hermano Juan I y unificaba en 1409 en Sicilia la isla a la Corona tras la muerte de su hijo Juan. Las vísperas sicilianas de 1282 están en relación causal con Carlos I de Anjou. Éste hermano del rey francés Luis IX es un claro ejemplo de la defensa del establecimiento de una casa real de rango superior. El condado de Anjou que Felipe IX arrebató en 1204 en unión con el condado de Maine de los Plantagenets constituyó el punto de partida de un reino disperso formado por elementos pertenecientes a distintas bases jurídicas. Anjou tuvo en 1246 a su hermano Carlos como vasallo de la Corona cuando se casó con Beatriz, hija heredera de la Provenza. La ya esperada adquisición de Provenza - situada en el Imperio y perteneciente a la casa de Barcelona- debía ser ligada a los paisajes franceses. Carlos aún no se disponía a desligarse de la casa real francesa; llevaba en su emblema a lo largo de su vida los lirios dorados de los Anjou, que como Anjou, representaba también las posteriores ramificaciones en los Balcanes y en Hungría, aunque ya no tenía nada que ver con el condado francés. La autocomprensión se transformaba de la misma manera que el punto esencial de la soberanía de la Provenza se trasladaba a Italia. En 1253 se le ofreció a Carlos por primera vez el reinado de Sicilia, pero en el sur de Italia aún mandaban los Hohenstaufen y los papas negociaban con la corte real inglesa por encargo de Sicilia, atrasando así la llegada de la corona de Sicilia hasta 1266. En Roma la simpatía por los Anjou no era uniforme; por eso Carlos se preocupaba por obtener fama entre los senadores en Roma, que finalmente consiguió en 1268 tras el triunfo sobre los Conrados, y que tras varios asaltos también obtuvo en 1269 del Papa por la vicaría del Imperio de los Toscana. Proclamar rey de Cerdeña a su segundo hijo debía haber sido una medida de resistencia contra Jaime II, pero el compromiso matrimonial de Carlos de Salerno con la hija heredera de Esteban IV de Hungría y el del heredero de la corona húngara Ladislao con la tercera hija de Carlos de Anjou debía provocar presión sobre Bizancio, pero que esto iniciara la línea colateral húngara de los Anjou no se podía saber. Al mismo tiempo Carlos hacía planes matrimoniales con los monarcas de Siberia y Bulgaria casando en 1271 a su hijo Felipe, rey de Cerdeña, con la hija heredera de los condes de Achaia. Tras la muerte del basileo Miguel II en 1272 los habitantes de Albania aceptaron a Carlos como siguiente rey, con lo que se fijó la posterior línea albánica de los Anjou. Se puede observar como fue cercado sistemáticamente Bizancio; y de hecho en 1273 Beatriz, segunda hija de Carlos, tuvo que casarse con el hijo mayor del emperador titular latino de Constantinopla. No es de extrañar que los bizantinos afrontaban en 1274 la demanda de la unión eclesiástica, lo que significaba un mayor apoyo contra los Anjou. Pero para Carlos, Bizancio no era el propósito definitivo, sino Jerusalén; pues Carlos compró a principios del año 1277 a María de Antioquía, que buscaba hacer valer sus derechos contra el rey Hugo III de Chipre ante la corona de Jerusalén, este título. No era más que un título, pero tenía un gran valor ideológico para los Anjou.

Carlos de Anjou se hizo cargo del regnum siciliano a expensas de los Hohenstaufen. Lo que el papado no podía prever, es que Carlos no se hizo cargo sólo del reino, sino 
también de la supraestructura ideológica; esto equivale a ser la última estación antes del salto sobre el mar hasta tierra santa. La cruzada del emperador Enrique IV, y sobre todo la de su hijo Federico II no servía tanto a la liberación de la tumba santa, como al cumplimiento de la profecía del emperador en la antigüedad tardía. En la visita de Federico II al santo sepulcro, éste inició el comienzo del imperio mesiano y de la era de paz escatológica. A diferencia de Federico II, no hubo declaraciones en esta dirección por parte de Carlos de Anjou, pero estos pensamientos no eran inusuales en los contemporáneos de la segunda mitad del s. XIII, y mediante ello también pusieron en contacto a miembros de la casa de Barcelona.

Para poder enfrentrarse con las mismas armas a Alfonso $X$ de Castilla, que como nieto del rey Felipe de Suabia tenía derecho sobre la herencia de los Hohenstaufen, Jaime I casó en 1262 a su hijo Pedro, sucesor del trono con Constanża, hija del rey Manfredo. Como se mostró varios años después, era la única superviviente heredera de los Hohenstaufen y supuso hasta cierto punto la legitimación para la adquisición de Sicilia, que fue tomada en el s. XII como objetivo. La víspera siciliana era el vehículo decisivo que paró la expansión de los Anjou y facilitó la supremacía de la casa de Barcelona, aunque el papado hizo todo lo posible por eliminar la dinastía de los Hohenstaufen. Lo que es menos conocido es que todo este proceso mostró también la parte de la vertiente del derecho familiar. Debe destacarse que Jaime Il de Aragón consiguió en 1297 la investidura del reino de Cerdeña de Bonifacio VII y su hermano Federico III de Sicilia accedió a la petición de ayuda basilea, estableció en la vecindad de Achaia los ducados de Atenas y Neopatra e impuso, en contra de la voluntad de la compañía catalana, la liga feudal de los dos ducados al reino de Sicilia. ¿Es absurda la suposición de poder ver en parte un cuidadoso traspaso del entendimiento de la casa de Anjou. ¿O, mejor dicho, apropiarse del mundo imaginado por los Hohenstaufen? Porque, en cierta manera, ese tuvo que ser también el modelo de Cortes de Anjou.

Ya el nombre Federico es digno de atención. Era un nombre característico de los Hohenstaufen, que de los hermanos menores de Alfonso X, salvo Enrique, llevaba Federico, llamado Fradique, quién luchó al lado de Manfredo en 1266, y después de la derrota de Benevent huyó a Túnez, y de allí regresa a Sicilia, maquinando en 1267 una, para los Anjou, peligrosa revuelta. El hermano de éste, Jaime II, no quería libertarle en 1291 para Sicilia cuando él mismo tuvo que subir al trono a Alfonso III; Sicilia debía quedar directamente unida a la corona de Aragón, pero la tuvo que rechazar totalmente en 1295 en el tratado de Anagni, para evitar tanto la excomunión papal como la presión francesa y castellana, la isla de Sicilia en beneficio del poder papal. Se le adjudicó como número de orden III, lo cual como rey de Sicilia no le correspondía en absoluto. El número de orden II le correspondía al Hohenstaufen Federico, por su Kaiserorgnung. En ése número de orden también debía pensar Federico III, al que el día de su coronación al almirante aragonés Roger de Lauria, ante los estamentos sicilianos, declaró ser aquel Federico del que las profecías hablaban como Advenimiento y Señor del Imperio y de la mayor parte de la Tierra. Él por su parte se manifestaba en favor de la paz y la Concordia de la Cristiandad, con el fin de reconquistar la tierra santa. Escribió a su hermano Jaime II con la certeza de que el hundimiento 
del linaje galo de los Anjou estaba cercano. Esto es comprensible por el transfondo escatológico con la espera del fin del mundo. El franciscano Petrus Johannis Olivi denomina ya poco antes de 1298 a Federico Il como el «último emperador», que había perseguido a la Iglesia y volvería a perseguirla, si como afirmaban distintas profecías, resucitaba. Incluso Alfonso $X$ de Castilla fue insultado como anticristo por Gerardo de San Donnino, porque fluía sangre de los Hohenstaufen por sus venas. En el lado opuesto Federico II era considerado como un reformador de una iglesia desmoralizada, y a ella apelaba Federico III seguramente con un peyorativo dedo índice señalando a los Anjou. Pues también ellos habían sido incluidos en la espera del fin del mundo y precisamente como contrafigura de los Hohenstaufen. Ya que el canónigo de Colonia, Alejandro de Roes escribía hacia 1281 que del linaje de Carlomagno y de la casa real francesa surgiría un emperador llamado Carlos, que dominaría toda Europa y renovaría tanto al reino como a la iglesia. Después de él nadie reinaría, pues habría llegado el fin del mundo.

Carlos I de Anjou fue bautizado con el nombre de Esteban, tuvo que aceptar el nombre de Carlos aun antes de la adquisición del condado de Provenza, por lo visto porque debía resaltar la tardía inclusión de los Kapetinger en la descendencia de los carolingnos. Ya de manera modificada aparece este motivo en el año 1281. El nieto de Carlos se llamó Carlos Martell nombrado así —como así se pensó entonces- en memoria del patriarca de los carolignos. Y Carlos Martell se casó con Clemencia, la hija del rey alemán Rodolfo de Austria. Sobre todo traía la desposada el regnum Arelatense como dote, formalmente todavía en reino del Imperio, que a largo plazo debía proporcionar a los Anjou un paso al Imperio occidental.

Los franceses y Carlos de Anjou estaban acostumbrados a la sucesión hereditaria, pero el Imperio occidental era un imperio electivo, a lo que justamente en aquella década daban gran importancia los príncipes electores. Le negaron al rey alemán el dinero para un viaje a Roma para su coronación imperial, ya que al emperador electo no se le podía negar la elección de su hijo como sucesor. Pero el círculo de candidatos era limitado, ya que sólo entraban candidatos de linaje aptos para ser reyes. Por ello sólo se turnaban los Austria, los Wittelsbacher y los Luxemburgo en la posesión de la corona alemana. Los Austria descienden de Rodolfo de Rhreinfelden, el antirey del emperador Enrique IV; pero esto debió ser subrayado claramente, ya que el otro candidato a la elección de 1273, Otocar de Bohemia, incluso se había burlado de la insignificancia de los Austria. Por ello en las vísperas de la coronación, Rodolfo de Austria cambió el nombre de su esposa e hija, ambas llamadas Gertrudis, a Inés y Ana respectivamente; pues así se llamaban en 1218 las últimas herederas de la casa ducal de Zähringer, que había heredado en el s. XI de Rodolfo de Rheinfelden, quién había sido bendecido con una hija. Algo parecido observamos en la casa de los Luxenburgo. Carlos IV fue bautizado bajo el nombre de Wenceslao en 1316, y utilizó reiteradas veces este nombre como rey de Bohemia; pero en 1323, cuando fue desposado en París con la hija de Carlos de Valois, tomó el nombre de Carlos, probablemente porque tanto su padre, el rey Juan de Bohemia, hijo del emperador Enrique VII, como también su suegro aspiraban a conseguir la corona imperial, por lo que podía 
confiar en aspirar a dicha corona imperial algún día. El nuevo nombre señala sin lugar a dudas a Carlomago. En 1347 Carlos IV recibió en Praga la corona del Santo Wescenlao, a la que nunca renunció, y se hizo nombrar rey de Alemania en 1349 en Frankfurt, y un mes después se hizo coronar en Aquisgrán. En memoria de su elección hizo instalar en una pared libre de adornos de la catedral de Frankfurt situada a la derecha del coro, por encima de los asiento, una representación metafórica de Carlomagno y justo enfrente, a la izquierda del coro, a sí mismo. De camino a Aquisgrán hizo erigir una estatua de Carlomagno en la torre sur de la catedral de Colonia, y en Aquisgrán encargó la construcción de un coro gótico en la vieja iglesia imperial de los carolingios, imitando a la Chapelle Royal de Paris. Se había hecho artificialmente un descendiente de los carolingios, lo mismo que ya hiciere Carlos de Anjou cien años antes.

Algo más fácil lo tuvo la casa de Wittelsbach. De su casa ducal bávara descendía Isabel, esposa del rey Conrado IV, inmediato sucesor de Federico II. Poco después del nacimiento de Conradín, último heredero masculino de los Hohenstaufen, murió Conrado, en 1258 y la viuda de éste se casó con el conde del Tirol. Conradín quedó bajo la tutela de los Wittelbacher bávaros, que se sentían los protectores del legado alemán de los Hohenstaufen en el sur de Italia. Los Wittelsbacher le prometieron ayudar a formar su ejército, así como administrar sus bienes y territorios en el sur de Alemania en su ausencia, si éste les legaba los títulos de esa zona en caso de que Conradín que por aquel entonces no tenía hijos legítimos no regresase vivo de la atrevida empresa de Italia. Como esto de hecho ocurrió, pudieron considerarse realmente como continuación de la casa de Hohenstaufen.

Todo esto parece algo aventuresco, pues la consanguinidad ya solo juega un papel parcial en esta manera de pensar y querer hacer política. El derecho familiar abarcaba más, la sucesión en el cargo o la toma de posesión de una gran parte del legado material podía sustituir o suplir la escasez de consanguinidad. Los Austria fueron los que más lejos llevaron esta práctica, difundiendo hacia 1300 la leyenda de que descendían los de Colonna, sabiendo que éstos ya afirmaron en el s. XI ser descendientes de la casa imperial juliana, esto es, descender del César. Cuanto más alta era la meta política más atractivo debía ser el modelo de una casa soberana más antigua que legitimara el incremento de dignidad y en el incremento de la extensión territorial.

A raíz de los tres fenómenos observamos dos tendencias históricas de las instituciones, que se hicieron notables en toda Europa occidental a lo largo de toda la Alta Edad Media. Por un lado vemos la transpersonalización del reinado en reinados regionales, que se manifiesta en que el monarca debía compartir parcialmente su derecho a gobernar la población. En tanto en cuanto en esto existe el germen de la soberanía popular, dicha tendencia tendrá, desde un punto de vista histórico, un gran futuro. Por otro lado dicha característica suprapersonal dificulta la variación de las fronteras; el paso de Alicante del reino de Murcia al reino de Valencia - estudiado detenidamente por Juan Manuel del Estal- o la incorporación de Mallorca al principado catalán parecen ser más bien excepciones a esta tendencia. Sobre esto destaca - esto sería lo segundo- la parte dinástica del soberano, que aporta a la participación periférica de 
la población en el gobierno una mayor movilidad y sobre todo un radio de acción realmente europeo. Sólo el hecho de que la variedad de títulos legales pudieron ser implantados en otro plano jurídico sin cambios, permitió la creación de grandes reinos, por ejemplo desde la Provenza hasta los Balcanes del cercano Oriente, o desde el condado de Luxemburgo, entre la frontera franco-alemana, pasando por Bohemia hasta Polonia y Hungría, o desde el alto Rín pasando por Austria hacia Bohemia y Hungría. Aquí se miraba hacia atrás, pues se necesitaba la legitimación dada por una destacada personalidad de la historia, que se tratara como si fuera el fundador del linaje. Estas dos actitudes, una mirando al pasado y otra al futuro, es naturalmente propia de todas las épocas pero nunca en los extremos en los que se manifestó en la alta Edad Media de los s. XIII y s. XIV.

Traducción: Victoria Miralles 